University of Nebraska - Lincoln

DigitalCommons@University of Nebraska - Lincoln

4-2008

\title{
Subcritical and Supercritical Droplet Evaporation within a Zero- Gravity Environment: Low Weber Number Relative Motion
}

\author{
Hongtao Zhang \\ University of Nebraska-Lincoln \\ Vasudevan Raghavan \\ Indian Institute of Technology Madras, India \\ George Gogos \\ University of Nebraska-Lincoln, ggogos1@unl.edu
}

Follow this and additional works at: https://digitalcommons.unl.edu/mechengfacpub

Part of the Mechanical Engineering Commons

Zhang, Hongtao; Raghavan, Vasudevan; and Gogos, George, "Subcritical and Supercritical Droplet Evaporation within a Zero-Gravity Environment: Low Weber Number Relative Motion" (2008). Mechanical \& Materials Engineering Faculty Publications. 19.

https://digitalcommons.unl.edu/mechengfacpub/19

This Article is brought to you for free and open access by the Mechanical \& Materials Engineering, Department of at DigitalCommons@University of Nebraska - Lincoln. It has been accepted for inclusion in Mechanical \& Materials Engineering Faculty Publications by an authorized administrator of DigitalCommons@University of Nebraska Lincoln. 
Published in International Communications in Heat and Mass Transfer 35:4 (April 2008), pp. 385-394;

doi 10.1016/j.icheatmasstransfer.2007.08.002 Copyright (C) 2007 Elsevier Ltd. Used by permission.

http://www.elsevier.com/locate/ichmt

Published online September 12, 2007. Communicated for ICHMT by W. J. Minkowycz.

\title{
Subcritical and supercritical droplet evaporation within a zero-gravity environment: Low Weber number relative motion
}

\author{
Hongtao Zhang, Vasudevan Raghavan, ${ }^{*}$ and George Gogos \\ Walter Scott Engineering Center, Department of Mechanical Engineering, \\ University of Nebraska-Lincoln, Lincoln, NE 68588-0656, USA \\ * Currently Assistant Professor in Indian Institute of Technology Madras, India. \\ Corresponding author-G. Gogos, ggogos1@unl.edu
}

\begin{abstract}
A validated comprehensive axisymmetric numerical model, which includes the high pressure transient effects, variable thermo-physical properties and inert species solubility in the liquid phase, has been employed to study the evaporation of moving $n$-heptane droplets within a zero-gravity nitrogen environment, for a wide range of ambient pressures and initial freestream velocities. At the high ambient temperature considered $(1000 \mathrm{~K})$, the evaporation constant increases with the ambient pressure. At low ambient pressure, the evaporation constant becomes almost a constant during the end of the lifetime. At high ambient pressures, the transient behavior is present throughout the droplet lifetime. The final penetration distance of a moving droplet decreases exponentially with increasing ambient pressure. The average evaporation constant increases with ambient pressure. The variation is almost linear for reduced ambient pressures smaller than approximately 2. For higher values, depending on the initial freestream velocity, the average evaporation constant either becomes a constant (at low initial freestream velocities) or it non-linearly increases (at high initial freestream velocities) with the ambient pressure. Droplet lifetime decreases with increasing ambient pressure and/or increasing initial freestream velocity.
\end{abstract}

Keywords: droplet evaporation, high pressure, zero-gravity, axisymmetric model

\section{Introduction}

The understanding of droplet evaporation characteristics in high pressure and high temperature environments is important in the study of many industrial applications such as diesel engines and high speed combustors of aircraft jet engines. Transient characteristics of liquid- and gas-phases, the non-ideal behavior of the gas-phase, the real gas effects on the heat of vaporization and on the vapor-liquid equilibrium conditions at the droplet interface, and the solubility of the ambient inert species into the liquid droplet, become important at high pressure and high temperature environments. Studies on droplet evaporation at high pressures have been reported by several authors [1-3]. Several investigators [4-12], have addressed the problem of gas solubility in their research works on high pressure droplet vaporization. Nomura et al. [13] have measured experimentally the temporal variation of $\left(d / d_{0}\right)^{2}$ for an $n$-heptane droplet at different ambient pressures and temperatures under microgravity conditions. Several investigators have reported about the transition from subcritical to supercritical vaporization regime and several others have studied the characteristics of droplet gasification at supercritical conditions [14-25]. Numerical research on liquid droplet evaporation in a high temperature convective environment has been carried out by Shih 
and Megaridis [26]. They have employed a hybrid discretization scheme to improve representation of the physical liquid phase energy transport processes. The implications to the overall droplet vaporization behavior are also discussed. Pope and Gogos [27] have developed a new multicomponent diffusion formulation for the finite-volume method and have applied the same to convective droplet combustion. Recently, Zhang and Gogos [28] carried out numerical research on a vaporizing droplet in a forced convective environment. A comprehensive numerical model to study a vaporizing $n$-heptane droplet in a forced convective environment has been presented. The validation of their numerical results with the experimental results [13] is also reported. In the experiments [13], the droplet had been moved from the droplet-generator to a test portion for a short period of time, which imparted an initial small relative velocity between the droplet and the surrounding gas. When such a small relative motion was included in the numerical model, their model was able to predict the experimental time histories quite accurately. Further investigations on the evaporation of a suspended droplet in forced convective high pressure environments have been carried out by Zhang [29].

In this study, vaporization of moving $n$-heptane droplets within a zero-gravity nitrogen environment has been presented. A numerical model which has been developed and thoroughly validated [28, 29]against the experimental results available in the literature [13], has been employed for the simulations. Vaporization of an $n$-heptane droplet with an initial diameter of $100 \mu \mathrm{m}$ and at an initial temperature of $300 \mathrm{~K}$, within a zero-gravity, $\mathrm{N}_{2}$ environment at $1000 \mathrm{~K}$ has been studied for a wide range of ambient pressures $(0.1-9 \mathrm{MPa})$ and initial freestream velocities $(0.25-5 \mathrm{~m} / \mathrm{s})$. Initial freestream velocities larger than $5 \mathrm{~m} / \mathrm{s}$ have not been considered in order to maintain the value of Weber number $\left(W e=\rho_{\infty} U_{\infty}^{2} d / \sigma_{\mathrm{s}}\right)$ less than 1 . When Weber number is less than approximately 1, even at Reynolds numbers as high as 400, droplet would remain nearly spherical [30].

\section{Numerical model}

A liquid fuel droplet with an initial diameter $d_{0}$ is evaporating and moving within a hot inert environment of infinite expanse. The initial temperature of the droplet is $T_{0^{\prime}}$ and the ambient pressure and temperature are $p_{\infty}$ and $T_{\infty}$, respectively. The relative velocity between the droplet and the surrounding medium is termed as the freestream velocity $U_{\infty}$. The drag acting on the moving droplet reduces this freestream velocity with time. Since, this study is focused on the zero-gravity environment, natural convection is absent. Initially both the liquid phase ( $n$-heptane fuel droplet) and the gaseous phase (nitrogen) consist of a single species. Due to the elevated pressure effects, the ambient inert gas (nitrogen) dissolves in the liquid phase. The following assumptions are employed in the numerical model: (1) the droplet shape remains spherical, (2) radiation effects are negligible, (3) second-order effects, such as the Soret and Dufour effects are negligible, (4) viscous dissipation is neglected and (5) the flow is laminar and axisymmetric.

A comprehensive axisymmetric numerical model has been developed to study droplet evaporation over a wide range of ambient temperatures and pressures. The model captures the transient high pressure vaporization process, by employing temperature and pressure dependent variable thermo-physical properties in the gas- and the liquid phases, the real gas effects and the solubility of inert species into the liquid phase. Changes in the liquid phase density due to both thermal expansion and change in species composition contribute to the rate at which the droplet surface recedes and are incorporated in the model. The unsteady equations of mass, species, momentum and energy conservation in axisymmetric spherical coordinates are solved using the finite-volume and SIMPLEC methods. The axisymmetric numerical model has been thoroughly validated against the extensive microgravity experimental data of Nomura et al. [13]. The details of the governing equations, solution method, evaluation of variable thermo-physical properties, convergence criteria, boundary and initial conditions, and validation are available elsewhere [28, 29]. An equation of state is required for closing the set of governing equa-

Table 1. Validation of the numerical model against the experimental results of Gokalp et al. [31]

\begin{tabular}{lllc}
\hline$d_{0}(\mathrm{~mm})$ & $U_{\infty}(\mathrm{m} / \mathrm{s})$ & $\begin{array}{l}\text { Lifetime }(\mathrm{s}) \\
\text { Experimental [29] }\end{array}$ & Numerical \\
\hline 1.43 & 2.53 & 19.20 & 19.98 \\
1.18 & 6.00 & 12.04 & 12.46 \\
\hline
\end{tabular}




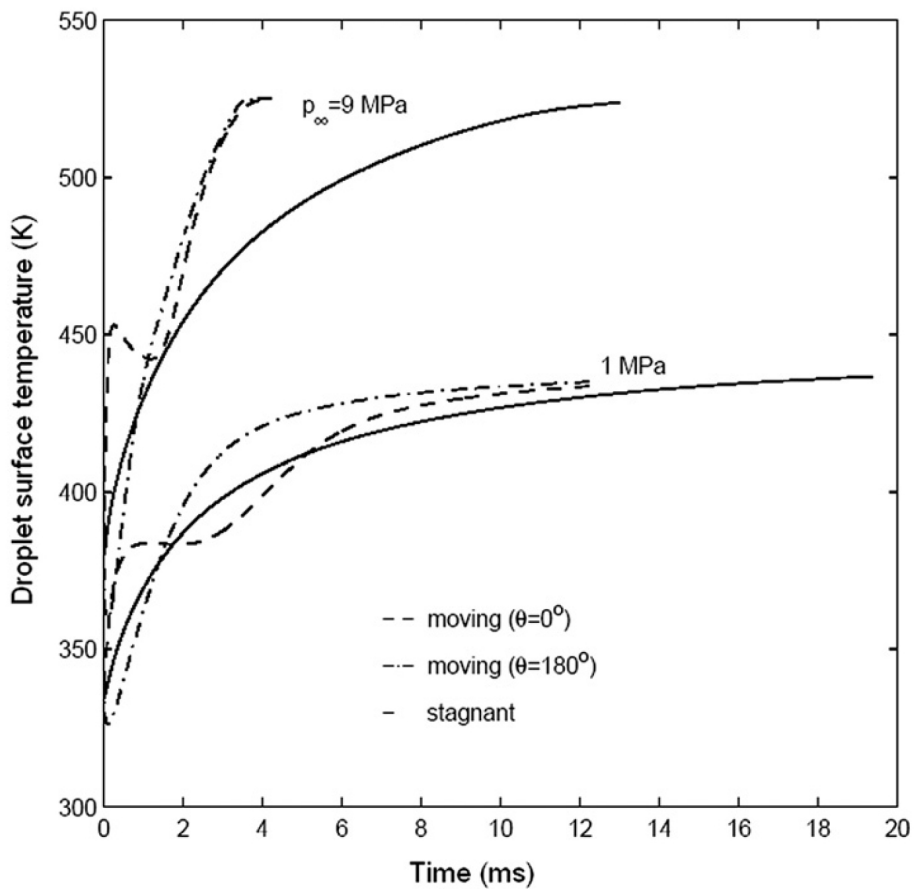

Figure 1. Temporal variation of droplet surface temperature at different ambient pressures; $d_{0}=100 \mu \mathrm{m}, T_{\infty}=1000 \mathrm{~K}$. Initial freestream velocity of moving droplet is $1.5 \mathrm{~m} / \mathrm{s}$.

tions and boundary conditions. Peng-Robinson equation of state has been employed because of its accuracy $[9,21,23]$. Transient calculations have been terminated when $\left(d / d_{0}\right)^{2} \leq 0.2$, or when the critical state for the binary system is reached.

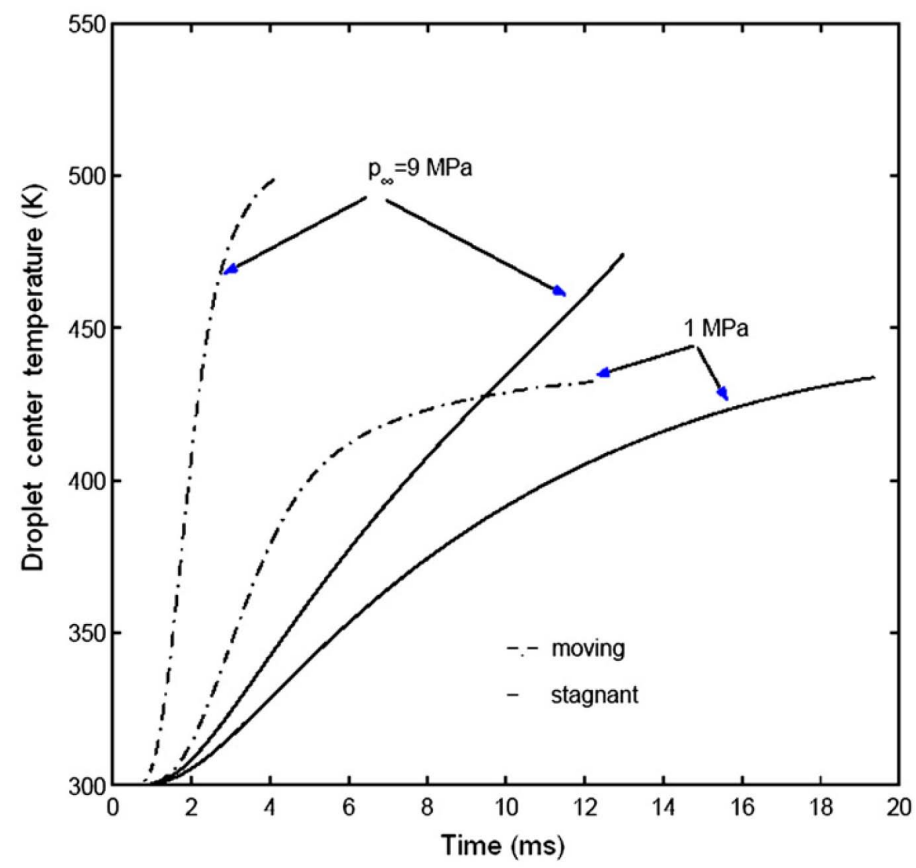

Figure 2. Temporal variation of droplet center temperature at different ambient pressures; $d_{0}=100 \mu \mathrm{m}, T_{\infty}=1000 \mathrm{~K}$. Initial freestream velocity of moving droplet is $1.5 \mathrm{~m} / \mathrm{s}$. 


\section{Results and discussion}

As mentioned earlier, the comprehensive numerical model has been thoroughly validated against the microgravity experimental data of Nomura et al. [13]. Additional validation of the model is presented in the present paper by comparing with the experimental results of Gokalp et al. [31]. Table 1 shows the
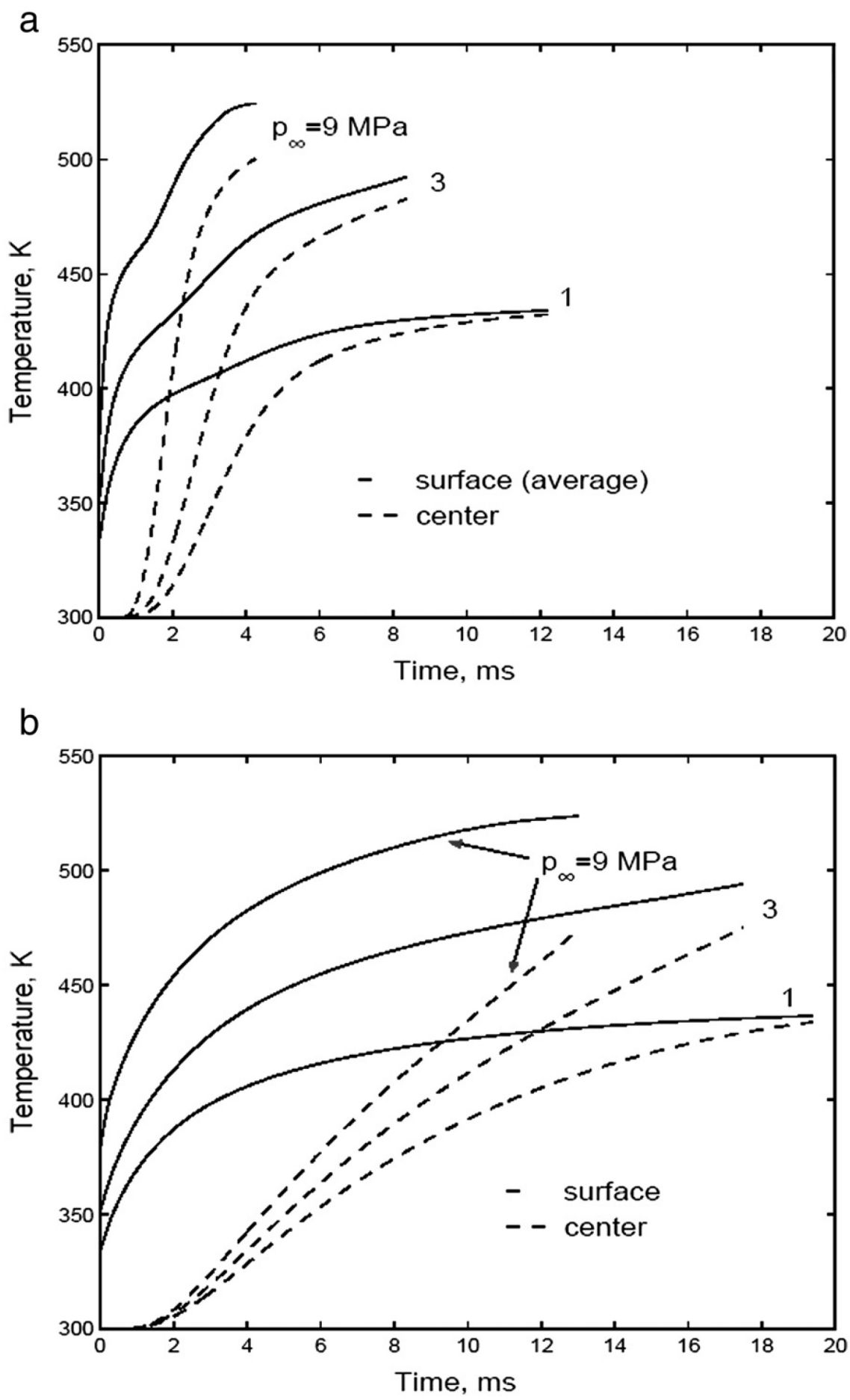

Figure 3. Temporal variation of temperature at different ambient pressures; $d_{0}=100 \mu \mathrm{m}, T_{\infty}=1000 \mathrm{~K}$ (a) moving droplet; initial freestream velocity $=1.5 \mathrm{~m} / \mathrm{s}(\mathrm{b})$ stagnant droplet. 
droplet lifetimes for 2 cases of initial droplet diameters and freestream velocities obtained from the numerical model and experimental results of Gokalp et al. [31]. The comparison between the numerical result and the experimental data is very good. The ambient gas employed in the numerical model is $\mathrm{N}_{2}$ and that used in the experiment [31] is air.
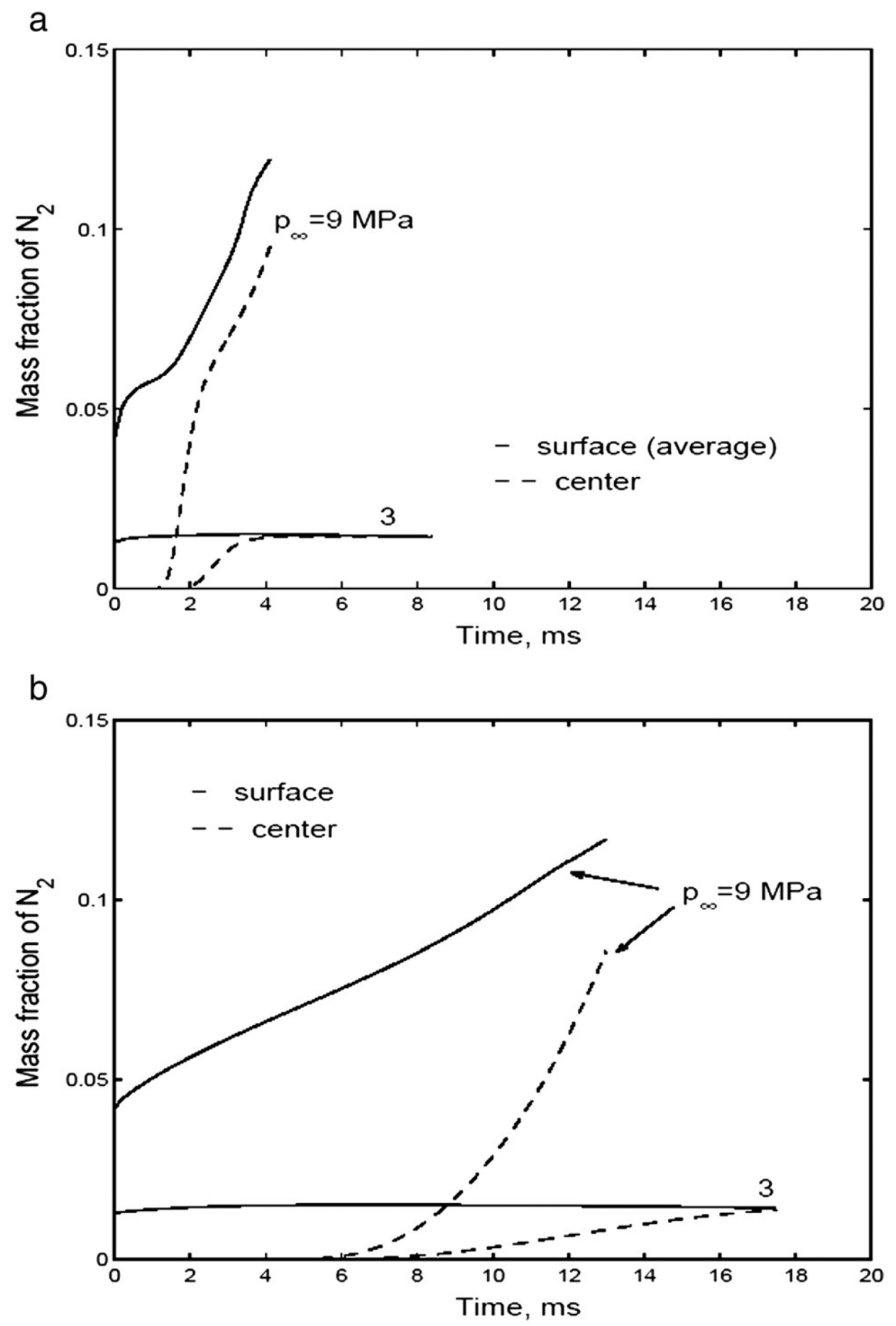

Figure 4. Temporal variation of temperature at different ambient pressures; $d_{0}=100 \mu \mathrm{m}, T_{\infty}=1000 \mathrm{~K}$, (a) moving droplet; initial freestream velocity $=1.5 \mathrm{~m} / \mathrm{s}$ (b) stagnant droplet. 
An $n$-heptane droplet with an initial diameter of $100 \mu \mathrm{m}$, initially at a temperature of $300 \mathrm{~K}$, moving with an initial freestream velocity of $1.5 \mathrm{~m} / \mathrm{s}$, within a zero-gravity nitrogen environment at $1000 \mathrm{~K}$, has been studied here. Figure 1 shows the temporal variations of the droplet surface temperatures (at the front and the rear stagnation points, $\theta=0^{\circ}$ and $180^{\circ}$, respectively), at two ambient pressures. Due to the contact of fresh ambient gas at the front stagnation point, the variation of surface temperature at this point is different when compared to that at the rear stagnation point. During the later part of the lifetime, the surface temperatures at the front and rear stagnation points tend towards a same value, because of the considerable decrease in the relative velocity between the droplet and the surrounding gas and also due to the internal mixing. Temporal variation of the surface temperature of a droplet without any relative motion (stagnant droplet) is also shown in Figure 1. Non-zero relative velocity between the droplet and its hot environment increases the rate of evaporation for the moving droplet. Due to this, the lifetime of the moving droplet is less than that of the stagnant droplet. At the low ambient pressure, the difference in the variation of the surface temperature between the moving and stagnant droplet cases is not as significant as that at the high ambient pressure, where the surface temperature of the moving droplet increases much rapidly with time, when compared to that of a stagnant droplet. Also, at high ambient pressure $(9 \mathrm{MPa})$, the moving droplet reaches the critical state of the mixture, where the simulations have been stopped, whereas, the stagnant droplet has not attained critical state of the mixture at $\left(d / d_{0}\right)^{2}=0.2$.

The temporal variation of the temperature at the droplet center for the same cases as above is presented in Figure 2. The effect of the internal circulation is clearly seen here. The droplet center temperature rapidly increases for the moving droplet case when compared to the stagnant droplet for both ambient pressures considered because of the internal mixing.

Time histories of the average droplet surface temperature and the temperature at the droplet center for a moving droplet (initial freestream velocity $1.5 \mathrm{~m} / \mathrm{s}$ ) have been presented for three ambient pressures in Figure 3a. Similar plot for a stagnant droplet is shown in Figure 3b. It is clear from Figure 3a that, because of increased energy transfer due to convection, the surface temperature increases rapidly with time for a moving droplet. Due to the internal circulation, the droplet center temperature also increases rapidly with time for a moving droplet. However, as the ambient pressure increases, the difference between the surface and center temperature increases and a substantial difference is maintained until the end of the droplet lifetime. It should also be noted that the difference between the surface and center temperatures is more predominant for the stagnant droplet case (Figure 3b), because of the absence of a thorough internal circulation.

The amount of ambient gas dissolved inside the liquid droplet increases with ambient pressure. Figure 4 shows the mass fraction of the ambient gas $\left(\mathrm{N}_{2}\right)$ at the droplet surface (average value) and at the droplet center for a moving droplet (Figure 4a) and stagnant droplet (Figure 4b), at two ambient pressures. At an

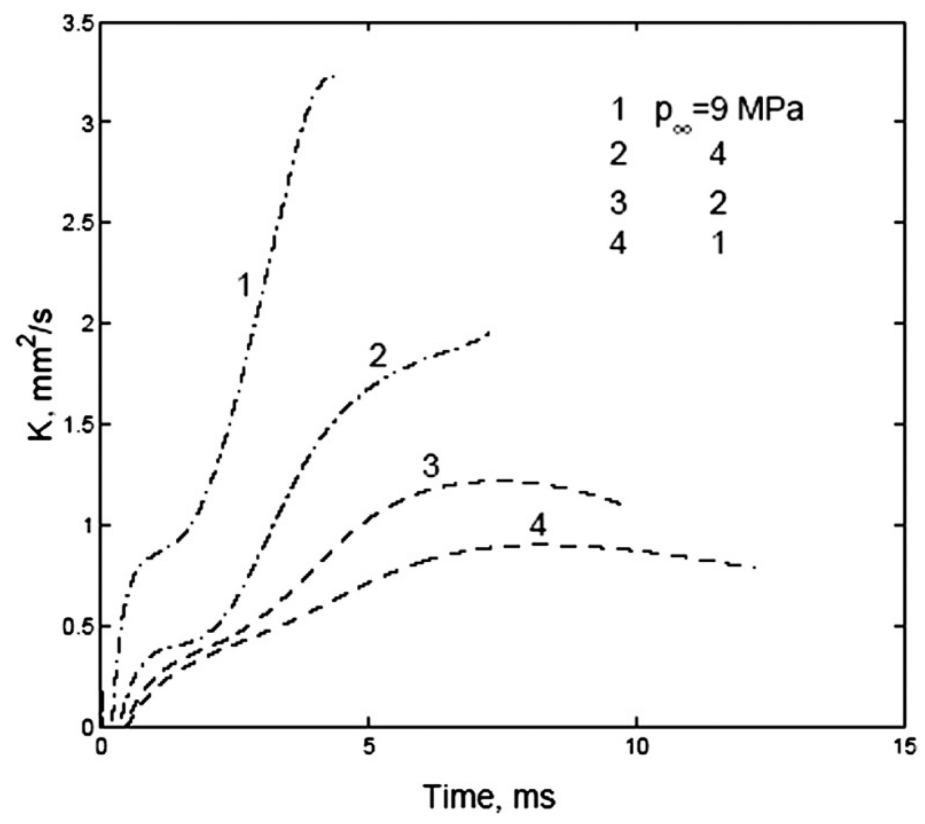

Figure 5. Temporal variation of the evaporation constant for a moving droplet at different ambient pressures; $d_{0}=100 \mu \mathrm{m}, T_{\infty}=1000 \mathrm{~K}$, initial freestream velocity $=1.5 \mathrm{~m} / \mathrm{s}$. 
ambient pressure of $3 \mathrm{MPa}$, only a small and nearly constant amount of $\mathrm{N}_{2}$ is observed on the droplet surface, for both moving and stagnant droplets. At the droplet center, the mass fraction of $\mathrm{N}_{2}$ increases and reaches the surface value more rapidly for a moving droplet, due to the presence of internal mixing. At a much higher ambient pressure $(9 \mathrm{MPa})$, the mass fraction of $\mathrm{N}_{2}$ increases at the droplet surface for both moving and stagnant droplets, but more rapidly for the moving droplet, due to the additional convective transport of the species. Similarly, the mass fraction of $\mathrm{N}_{2}$ at the droplet center continuously increases, even though it never reaches the surface value. Similar to $\mathrm{N}_{2}$ mass fraction at the surface, the growth of the $\mathrm{N}_{2}$ mass fraction at the droplet center is more rapid for the moving droplet.

Temporal variation of the evaporation constant $\mathrm{K}\left(\mathrm{mm}^{2} / \mathrm{s}\right)$ for a moving droplet has been plotted in Figure 5. For the high ambient temperature considered here $(1000 \mathrm{~K})$, as the ambient pressure increases, the
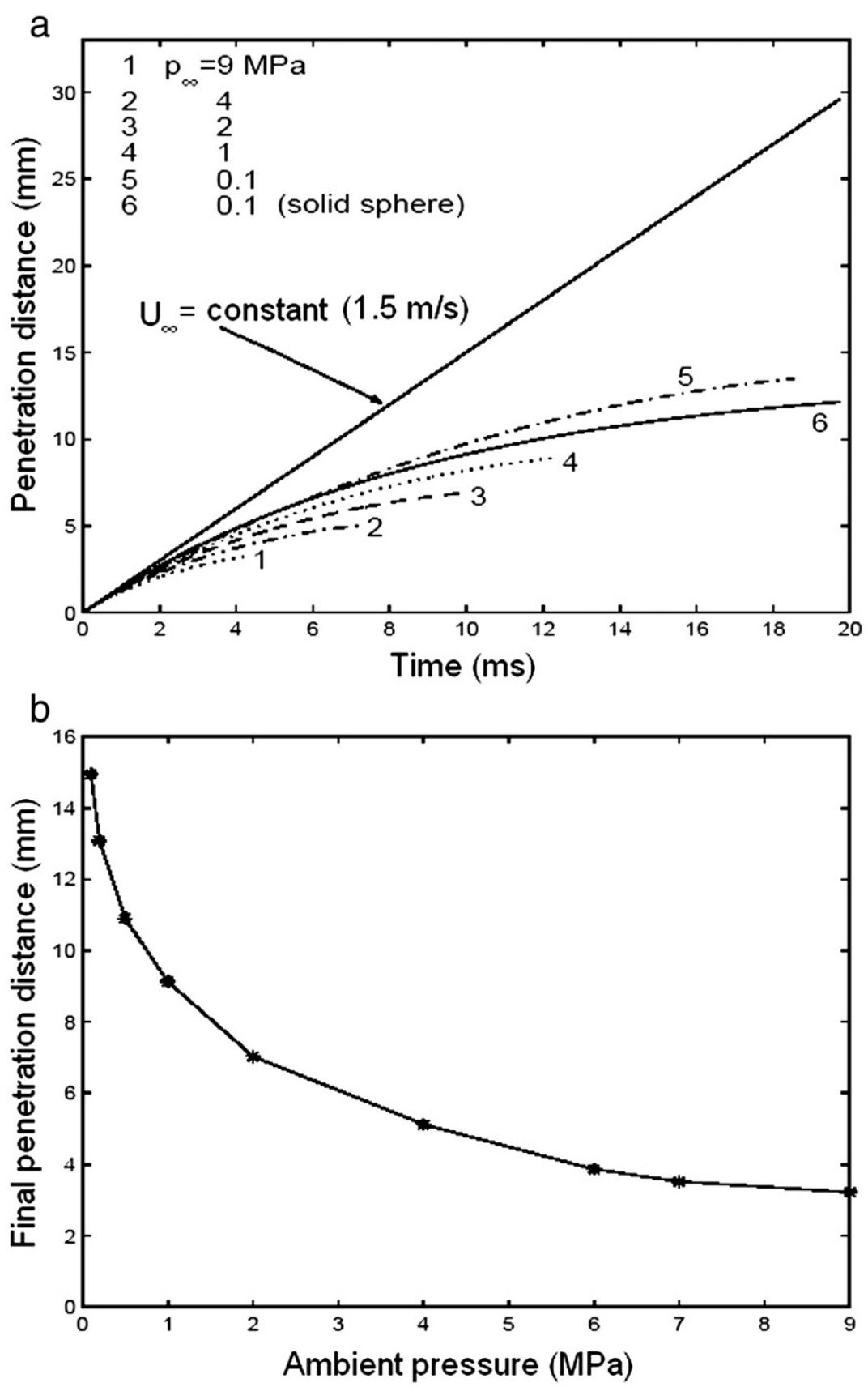

Figure 6. Variation of penetration distance for a moving droplet; initial freestream velocity $=1.5 \mathrm{~m} / \mathrm{s}, d_{0}=100 \mu \mathrm{m}$, $T_{\infty}=1000 \mathrm{~K}$, (a) temporal variation at different ambient pressures and (b) final penetration distance with the ambient pressure. 


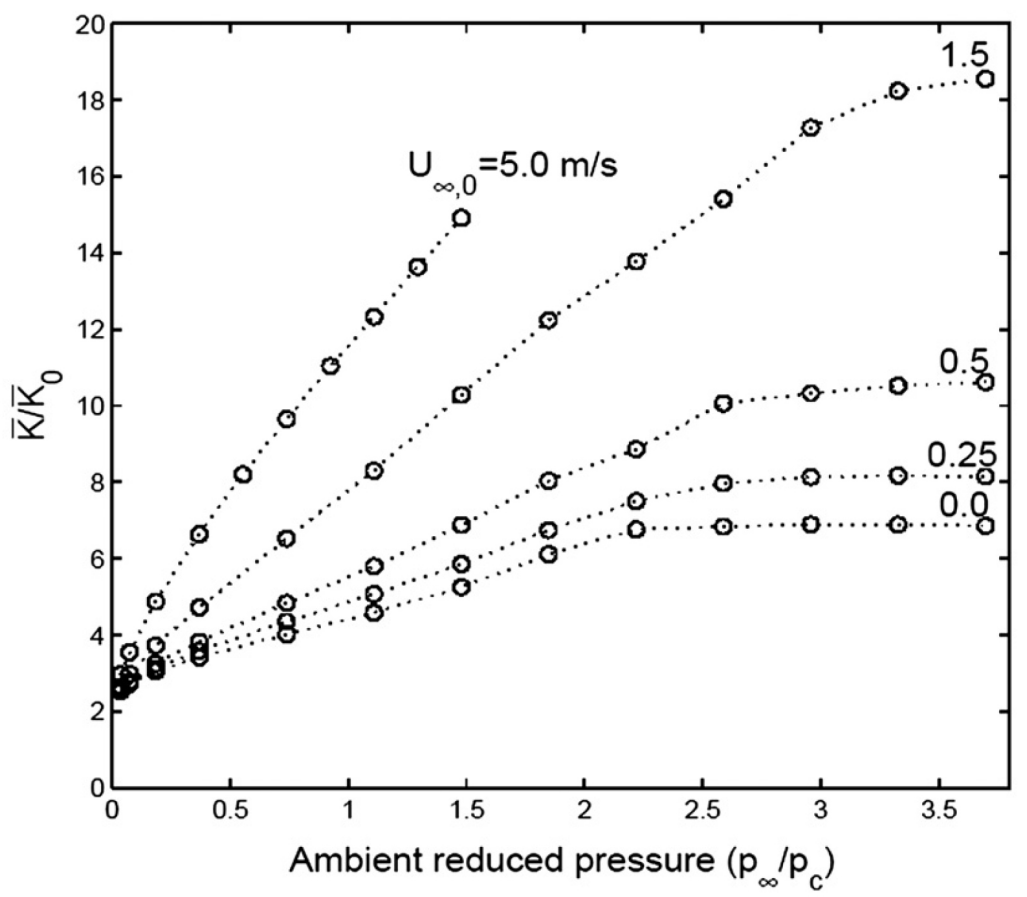

Figure 7. Variation of non-dimensional average evaporation constant with reduced ambient pressure for a moving droplet; $d_{0}=100 \mu \mathrm{m}, T_{\infty}=1000 \mathrm{~K}$, different freestream velocities.

evaporation constant also increases. It can also be observed that at low ambient pressures, the evaporation constant reaches an almost constant value during the end of the droplet lifetime. As the ambient pressure increases, the evaporation constant increases with time monotonically and steeply, throughout the droplet lifetime. As discussed earlier, the droplet lifetime significantly decreases with increasing ambient pressure.

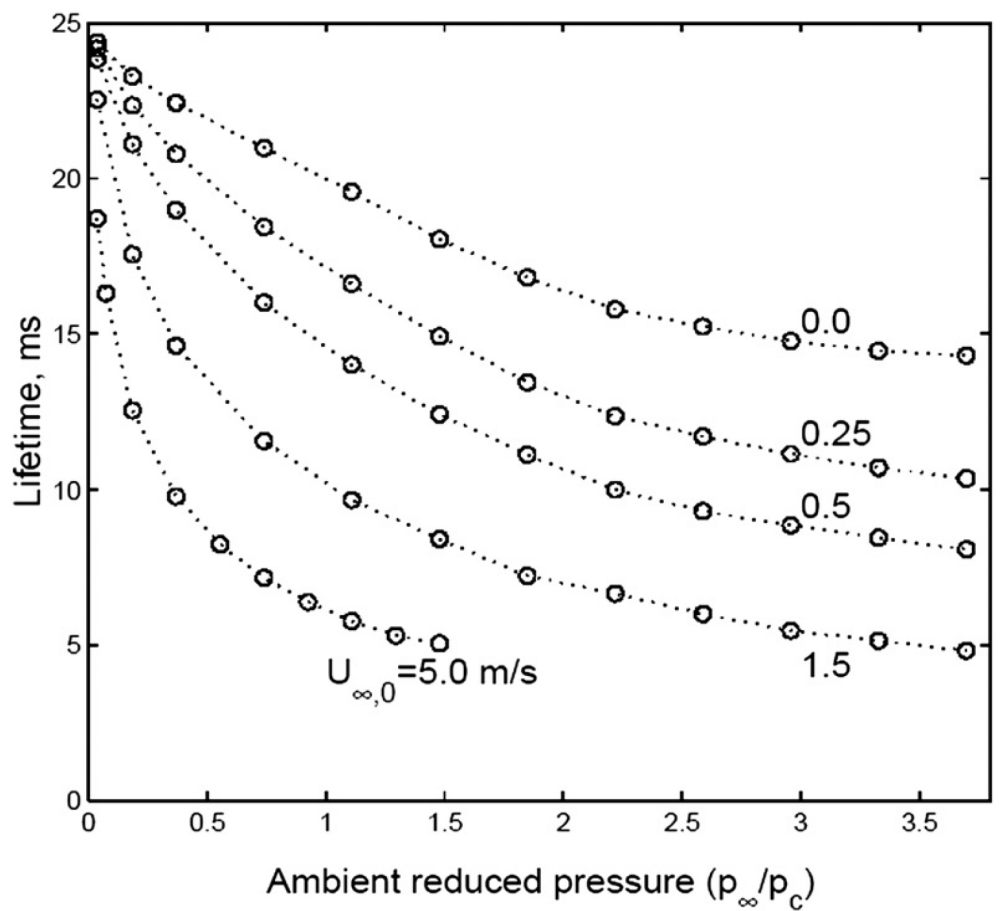

Figure 8. Variation of droplet lifetime with reduced ambient pressure for a moving droplet; $d_{0}=100 \mu \mathrm{m}, T_{\infty}=1000 \mathrm{~K}$, different freestream velocities. 
Figure 6a presents the time history of the distance traveled by the moving droplet (penetration distance) at different ambient pressures. The curves numbered 1 to 5 represent the evaporating $n$-heptane droplets. Curve numbered 6 , shows the penetration distance with time for a solid sphere of diameter equal to the initial droplet diameter $(100 \mu \mathrm{m})$. It is clear from the plot that as the ambient pressure increases, the penetration distance decreases because of the increased rate of vaporization (shorter lifetime) at higher ambient pressures. In fact, Figure $6 \mathrm{~b}$ shows that the final penetration distance exponentially decreases with increasing ambient pressure. If a solid sphere with the same density and initial diameter as that of an $n$-heptane droplet is considered to be moving with the same initial velocity of $1.5 \mathrm{~m} / \mathrm{s}$, due to higher drag experienced by the solid sphere, its penetration distance (until its velocity reaches zero) is less than that of the $n$-heptane droplet (curves 5 and 6). The distance traveled with time, for a particle traveling with a uniform velocity of $1.5 \mathrm{~m} / \mathrm{s}$, without any drag, is also shown in the plot (straight solid line in Figure 6a).

An average evaporation constant $(\bar{K})$ has been obtained following Ristau et al. [11], by time-averaging the evaporation constant, for the time period during which the value of $\left(d / d_{0}\right)^{2}$ is less than 0.5 . The value of $\bar{K}$ has been non-dimensionalized using a reference evaporation constant value $\overline{(K}=0.1817 \mathrm{~mm}^{2} /$ s) obtained when the ambient temperature and pressure are $T_{\infty}=T_{c}$ and $p_{\infty}=1 \mathrm{~atm}$, respectively and $T_{0}=300 \mathrm{~K}$. Figure 7 shows the variation of the average evaporation constant with the ambient pressure for different initial freestream velocities. The non-dimensional average evaporation constant increases almost linearly with the reduced ambient pressure $p_{\infty} / p_{c^{\prime}}$ where $p_{c}$ is the critical pressure of $n$-heptane, till the ambient reduced pressure is approximately 2 . For higher reduced ambient pressures, it either reaches an almost constant value (at low initial freestream velocities) or increases non-linearly (at high initial freestream velocities). It is clear from Figure 7 that due to convection there is a significant increase in the average evaporation constant.

The variation of droplet lifetime with reduced ambient pressure has been presented in Figure 8. At high initial freestream velocities, because of convective transport, the rate of evaporation increases, due to which the droplet lifetime decreases. Also, as the ambient pressure increases, there is almost an exponential decay in the droplet lifetime.

\section{Conclusions}

In this study, vaporization of moving $n$-heptane droplets within a zero-gravity environment has been presented. A numerical model, which has been developed and thoroughly validated [28, 29] against the experimental results available in the literature [13], has been employed for the simulations. Vaporization of an $n$-heptane droplet with an initial diameter of $100 \mu \mathrm{m}$ and at an initial temperature of $300 \mathrm{~K}$, within a zero-gravity, $\mathrm{N}_{2}$ environment at $1000 \mathrm{~K}$ has been studied for a wide range of ambient pressures (0.1$9 \mathrm{MPa}$ ) and initial freestream velocities $(0.25-5 \mathrm{~m} / \mathrm{s})$. In general, at the high ambient temperature (1000 K), the evaporation constant increases with the ambient pressure. At low ambient pressure, the evaporation constant becomes almost a constant during the end of the lifetime. At high ambient pressures, the transient behavior is present during the entire droplet lifetime. The final penetration distance of a moving droplet decreases exponentially with increasing ambient pressure. The average evaporation constant increases with ambient pressure and the variation is almost linear for reduced ambient pressure smaller than approximately 2. For higher values, depending on the initial freestream velocity, the average evaporation constant either becomes a constant (at low initial freestream velocities) or it non-linearly increases (at high initial freestream velocities) with the ambient pressure. Droplet lifetime decreases with increasing ambient pressure and/or increasing initial freestream velocity.

\section{Acknowledgments}

This research has been funded by NASA EPSCoR (NCC5-169) and ARO EPSCoR under Grant No. DAAD19-99-10116. Computational resources were provided by the Thermal-Fluids computational facility and the Research Computing Facility at the University of Nebraska-Lincoln.

\section{References}

[1] H. Jia and G. Gogos, Investigation of liquid droplet evaporation in subcritical and supercritical gaseous environments, Journal of Thermophysics and Heat Transfer 6 (1992), pp. 738-745. 
[2] S. D. Givler and J. Abraham, Supercritical droplet vaporization and combustion studies, Progress of Energy and Combustion Sciences 22 (1996), pp. 1-28.

[3] J. Bellan, Supercritical (and subcritical) fluid behavior and modeling: drops, streams, shear and mixing layers, jets and sprays, Progress of Energy and Combustion Sciences 26 (2000), pp. 329-366.

[4] G. S. Canada and G. M. Faeth, Fuel droplet burning rates at high pressures, Proceedings of the Combustion Institute $\mathbf{1 4}$ (1973), pp. 1345-1354.

[5] E. W. Curtis and P. V. Farrell, Droplet vaporization in a super critical microgravity environment, Acta Astronautica $\mathbf{1 7}$ (1988), pp. 1189-1193.

[6] E. W. Curtis and P. V. Farrell, A numerical study of high-pressure droplet vaporization, Combustion and Flame 90 (1992), pp. 85-102.

[7] K. C. Hsieh, J. S. Shuen and V. Yang, Droplet vaporization in high pressure environments I: near critical conditions, Combustion Science and Technology 76 (1991), pp. 111-132.

[8] J. P. Delplanque and W. A. Sirignano, Numerical study of the transient vaporization of an oxygen droplet at sub- and super-critical conditions, International Journal of Heat and Mass Transfer 36 (1993), pp. 303-314.

[9] H. Jia and G. Gogos, High pressure droplet vaporization; effects of liquid-phase gas solubility, International Journal of Heat and Mass Transfer 36 (18) (1993), pp. 4419-4431.

[10] R. Ruszalo and W. L. H. Hallett, A model for the autoignition of single liquid droplets at high pressure, Combustion Science and Technology 86 (1992), pp. 183-197.

[11] R. Ristau, U. Nagel, H. Iglseder, J. Konig, H. J. Rath, H. Nomura, M. Kono, M. Tanabe and J. Sato, Theoretical and experimental investigations on droplet evaporation and droplet ignition at high pressures, Microgravity Science and Technology VI/4 (1993), pp. 223-228.

[12] F. Poplow, Numerical calculation of the transition from subcritical droplet evaporation to supercritical diffusion, International Journal of Heat and Mass Transfer 37 (1994), pp. 485-492.

[13] H. Nomura, Y. Ujiie, H. J. Rath, J. Sato and M. Kono, Experimental study of high-pressure droplet evaporation using microgravity conditions, Proceedings of the Combustion Institute 26 (1996), pp. 1267-1273.

[14] P. Haldenwang, C. Nicoli and J. Daou, High pressure vaporization of LOX droplet crossing the critical conditions, International Journal of Heat and Mass Transfer 39 (16) (1996), pp. 3453-3464.

[15] A. Umemura and Y. Shimada, Characteristics of supercritical droplet gasification, Proceedings of the Combustion Institute 26 (1996), pp. 1621-1628.

[16] T. B. Gradinger and K. Boulouchos, A zero-dimensional model for spray droplet vaporization at high pressures and temperatures, International Journal of Heat and Mass Transfer 41 (1998), pp. 2947-2959.

[17] J. Stengele, K. Prommersberger, M. Willmann and S. Wittig, Experimental and theoretical study of one- and two-component droplet vaporization in a high pressure environment, International Journal of Heat and Mass Transfer 42 (1999), pp. 2683-2694.

[18] W. A. Sirignano and J. P. Delplanque, Transcritical vaporization of liquid fuels and propellants, Journal of Propulsion and Power 15 (6) (1999), pp. 896-902.

[19] G. S. Zhu and S. K. Aggarwal, Droplet supercritical vaporization with emphasis on equation of state, International Journal of Heat and Mass Transfer 43 (2000), pp. 1157-1171.

[20] J. R. Yang and S. C. Wong, On the discrepancies between theoretical and experimental results for microgravity droplet evaporation, International Journal of Heat and Mass Transfer 44 (2001), pp. 4433-4443.

[21] G. S. Zhu, R. D. Reitz and S. K. Aggarwal, Gas-phase unsteadiness and its influence on droplet vaporization in sub- and super-critical environments, International Journal of Heat and Mass Transfer 44 (2001), pp. 3081-3093.

[22] K. Harstad and J. Bellan, The $\mathrm{d}^{2}$ variation for isolated LOX drops and polydisperse clusters in hydrogen at high temperature and pressures, Combustion and Flame 124 (2001), pp. 535-550.

[23] G. S. Zhu and S. K. Aggarwal, Fuel droplet evaporation in a supercritical environment, ASME Journal of Engineering for Gas Turbines and Power 124 (2002), pp. 762-770.

[24] L. Consolini, S. K. Aggarwal and S. Murad, A molecular dynamics simulation of droplet evaporation, International Journal of Heat and Mass Transfer 46 (2003), pp. 3179-3188.

[25] S. Hohmann and U. Renz, Numerical simulation of fuel sprays at high ambient pressure: the influence of real gas effects and gas solubility on droplet vaporization, International Journal of Heat and Mass Transfer 46 (16) (2003), pp. $3017-3028$.

[26] A. T. Shih and C. M. Megaridis, Finite difference discretization effects on multidimensional droplet evaporation modeling, Numerical Heat Transfer, Part A Applications 25 (2) (1994), pp. 151-169.

[27] D. N. Pope and G. Gogos, A new multicomponent diffusion formulation for the finite-volume method: application to convective droplet combustion, Numerical Heat Transfer, Part A Applications 48 (3) (2005), pp. 213-233.

[28] H. Zhang and G. Gogos, Numerical research on a vaporizing fuel droplet in a forced convective environment, International Journal of Multiphase Flow 30 (2004), pp. 181-198.

[29] H. Zhang, Evaporation of a suspended droplet in forced convective high-pressure environments, Combustion Science and Technology 175 (2003), pp. 2237-2268.

[30] D. S. Dandy and L. G. Leal, Buoyancy-driven motion of a deformable drop through a quiescent liquid at intermediate Reynolds numbers, Journal of Fluid Mechanics 208 (1989), pp. 161-192.

[31] I. Gokalp, C. Chauveau, J. R. Richard, M. Kramer and W. Leukel, Observations on the low temperature vaporization and envelope and wake flame burning of $n$-heptane droplets at reduced gravity during parabolic flights, Proceedings of the Combustion Institute 22 (1988), pp. 2027-2035. 